\title{
Influence of grain size on the triggering stress of stress-induced martensitic transformation and related mechanical properties in two newly developed Ti alloys
}

\author{
C. $\mathrm{Li}^{1}$, C. $\mathrm{Zhu}^{1}, \mathrm{H} . \mathrm{Xiao}{ }^{2,3 *}, \mathrm{~W} . \mathrm{Chen}^{4}, \mathrm{~W} \cdot \mathrm{Li}^{1 * *}$ \\ ${ }^{1}$ School of Energy and Power Engineering, Changsha University of Science and Technology, \\ Changsha, Hunan 410114, P. R. China \\ ${ }^{2}$ State Key Laboratory of Advanced Design and Manufacturing for Vehicle Bodies, Hunan University, \\ Changsha 410082, P. R. China \\ ${ }^{3}$ Hunan Provincial Key Laboratory of Intelligent Laser Manufacturing, Hunan University, Changsha 410082, P. R. China \\ ${ }^{4}$ Guangdong University of Technology, Guangzhou 510006, P. R. China
}

Received 31 December 2019, received in revised form 29 January 2020, accepted 29 January 2020

\begin{abstract}
The $\beta$ grain growth behavior of two newly developed titanium alloys with composition Ti-10V-1Fe-3Al and Ti-10V-2Cr-3Al (wt.\%) isothermally annealed at $900{ }^{\circ} \mathrm{C}$ for a different time was studied, and its effect on the triggering stress of stress-induced martensitic (SIM) transformation and related mechanical properties was evaluated. The results show that the grain size increases with the increase of annealing time. The measured grain size of Ti-10V-1Fe$-3 \mathrm{Al}$ alloy is larger than that of $\mathrm{Ti}-10 \mathrm{~V}-2 \mathrm{Cr}-3 \mathrm{Al}$ alloy under the same annealing conditions. The increase of the grain size leads to an increase of the triggering stress resulting in the martensitic transformation. The work hardening ability and compressive failure strain of the studied alloys decrease rapidly.
\end{abstract}

K e y wo r d s: titanium alloy, grain size, phase transformation, mechanical properties

\section{Introduction}

Titanium alloys are the most important structural metal material after steel and aluminum alloys. Since the 1950s, with the increasing need for high strength and low-density materials in the modern industry, titanium alloys have developed rapidly. Titanium alloys are widely used in aerospace, navigation, petrochemical industry, metallurgy, machinery, energy, and medical and health fields because of their excellent properties, such as low density, high specific strength, excellent corrosion resistance, high-temperature resistance, good low-temperature performance [1].

Nowadays, $\alpha+\beta$ titanium alloys are widely used in practice. Compared with $\alpha$ or $\beta$ type titanium alloys, these two-phase alloys have a higher specific strength, lower hot working cost, excellent aging hardening characteristics, and good formability. Their mechanical properties, such as strength, plasticity, toughness and fatigue resistance, are closely re- lated to their microstructures. The most important microstructural factors are the grain size, morphology and volume fraction of the primary and secondary $\alpha$-phases and the grain boundary $\alpha$-phase $[2-5]$. Recently, Neelakantan et al. [6] reported a new strengthening mechanism: stress-induced martensitic transformation (SIM). They believe that stress-induced martensitic transformation can improve the strength of the alloy while maintaining a high level of plasticity, and have done some research on it. This particular mechanical behavior has great potential in improving energy absorption efficiency and impact resistance of materials. In titanium alloys, the high-temperature $\beta$-phase can be quenched to room temperature as a metastable state. Under the action of external stress, metastable $\beta$-phase can produce martensitic transformation. Through the study of Ti-Ta [7], Ti-V [8], Ti-Mo [9], Ti-Nb [10], Ti-10V-2Fe-3Al [11, 12], and $\beta-C e z[13]$ alloys, it was found that the stress-induced martensitic transformation in titanium alloys exhibits

\footnotetext{
*Corresponding author: e-mail address: xiaohuilaser@126.com

${ }^{* *}$ Corresponding author: e-mail address: lwzzgiiajie@126.com
} 
Table 1. The chemical compositions of the fabricated new alloys (in wt.\%)

\begin{tabular}{lccccccccc}
\hline Alloys & $\mathrm{V}$ & $\mathrm{Fe}$ & $\mathrm{Cr}$ & $\mathrm{Al}$ & $\mathrm{N}$ & $\mathrm{C}$ & $\mathrm{O}$ & $\mathrm{Ti}$ & Bal. \\
\hline Ti-10V-1Fe-3Al & 9.97 & 0.97 & - & 3.02 & 0.014 & 0.051 & 0.11 & Bal. \\
Ti-10V-2Cr-3Al & 10.6 & - & 2.18 & 2.97 & 0.013 & 0.05 & 0.1 & \\
\hline
\end{tabular}

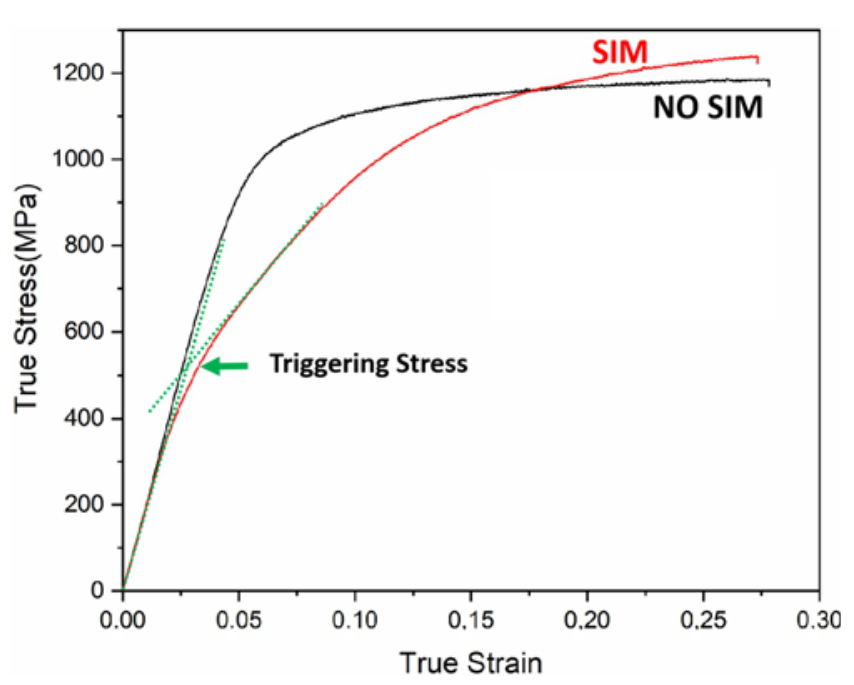

Fig. 1. Stress-strain curves of SIM and NO SIM samples $[11]$.

double yield points on the stress-strain curve, as shown in Fig. 1. The first yield point corresponds to the beginning of martensitic transformation (the triggering stress of the transformation), followed by a stage of high work hardening rate until the second yield point occurs, and then materials begin to slip and deform.

Many factors are affecting stress-induced martensitic transformation in titanium alloys, such as $\beta$-phase stability, $\beta$ grain size, alloying elements, strain rate, and deformation temperature. Among them, the $\beta$ grain size has a significant influence on stress-induced martensitic transformation. Previously, many studies have been done on it, but the conclusions were often different, and some even contrary. Grosdidier [14] studied the $\beta$-Cez alloy and found that the larger the $\beta$ grain size, the lower the triggering stress. However, in Ti-10V-2Fe-3Al alloy, Bhattacharjee [15] found opposite results. With the increase of $\beta$ grain size, the critical stress increased from 290 to $533 \mathrm{MPa}$ when the grain size increased from 130 to $300 \mu \mathrm{m}$. Paradkar et al. [16] studied three alloys, Ti-15Al-8Nb, Ti-15Al-12Nb, and Ti-18Al-8Nb. It was found that the influence of grain size on the triggering stress was U-shaped. When the grain size was less than $1000 \mu \mathrm{m}$, the triggering stress decreased with the increase of grain size, and when the grain size was larger than $1000 \mu \mathrm{m}$, the critical stress increased with the increase of grain size. To our best knowledge, until now, there is no straight answer on the effect of the $\beta$ grain size on stress-induced martensitic transformation, and the change of mechanical properties after phase transformation is also not clear. To solve this problem, two $\alpha+\beta$ titanium alloys with good comparability were studied in this paper. Samples with different grain sizes were obtained by high-temperature $\beta$ solution treatment for a different time. The effects of grain size on stress-induced phase transformation and its corresponding mechanical properties are systematically studied.

\section{Experimental details}

\subsection{Materials and microstructures}

In the current study, two novel multiphase titanium alloys Ti-10V-1Fe-3Al and Ti-10V-2Cr-3Al (wt.\%) reported by $\mathrm{Li}$ et al. [17] leading to different mechanical properties were fabricated on a laboratory scale by the Institute of Metal Research, Chinese Academy of Science, Shenyang, China. Each alloy weighing about $5 \mathrm{~kg}$ was obtained in a forged condition. The $\beta$-transus temperatures for the materials in their as-received state have been measured using dilatometry. The measured $\beta$-transus values of Ti-10V-1Fe-3Al and Ti-10V-2Cr-3Al alloys are approximately $830^{\circ} \mathrm{C} \pm 5^{\circ} \mathrm{C}$ and $810^{\circ} \mathrm{C} \pm 5^{\circ} \mathrm{C}$, respectively. Their chemical compositions are summarized in Table 1, and corresponding as-received microstructures and X-ray diffraction (XRD) phase analysis are shown in Fig. 2. It can be seen that the initial microstructures of both the alloys are very similar and composed of a high volume fraction of $\alpha$-phase, which has a mixed unregular morphology in the $\beta$ matrix.

From the thick as-received slab, cylindrical samples of $7 \mathrm{~mm}$ length and $4 \mathrm{~mm}$ diameter were machined using electrical discharge machining (EDM). The thin oxide outer layer was removed by careful mechanical polishing before further experimentation. The samples were heated to the solution annealing temperature of $900{ }^{\circ} \mathrm{C}$ at a heat rate of $15^{\circ} \mathrm{C} \mathrm{min} \mathrm{min}^{-1}$ and solution annealed for a different annealing time of 2, 15, 30, 50, 70, and 90 min using a Nabertherm furnace filled with argon gas. After solution annealing for a different time, the samples were water quenched to room temperature. For microstructural analysis, the samples were mounted into the cold-setting resin and polished fol- 

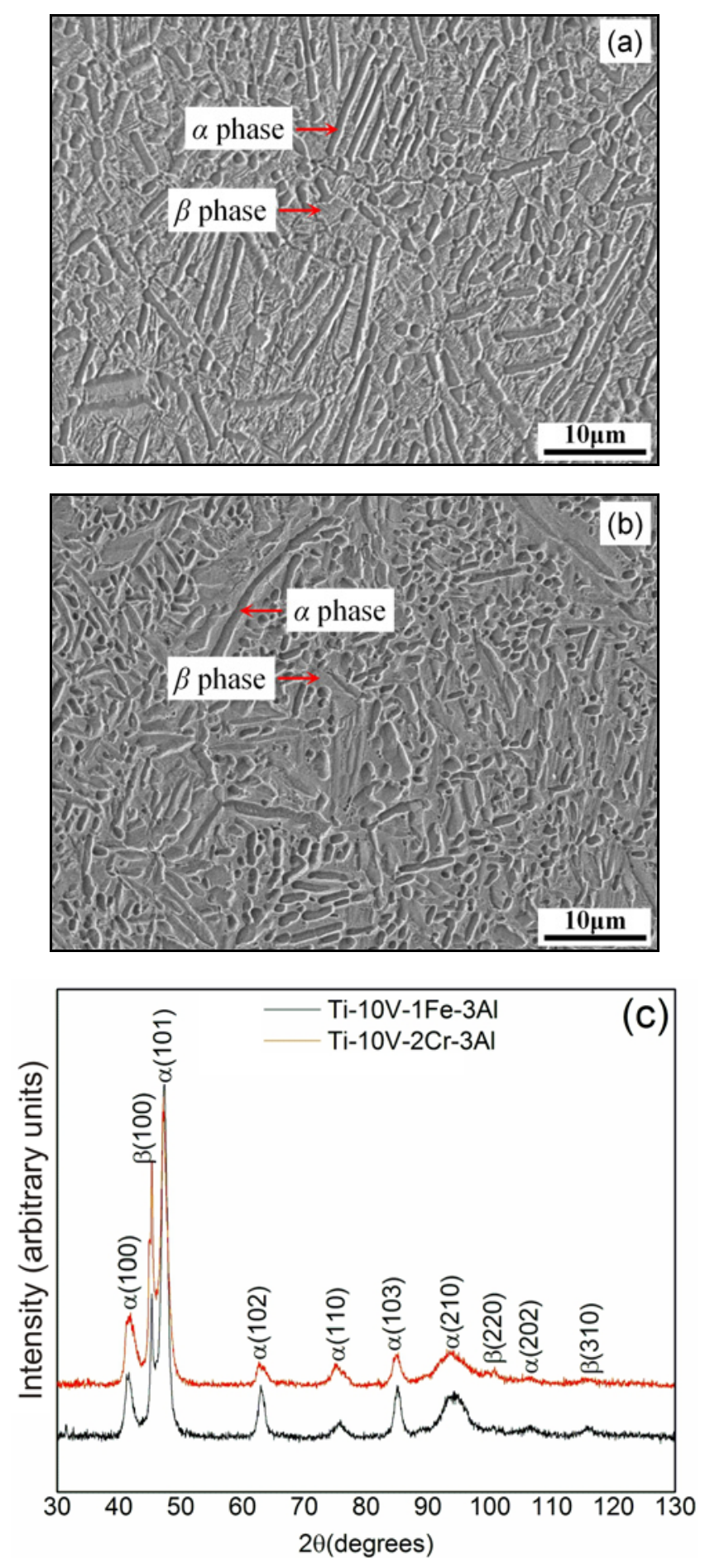

Fig. 2. (a) SEM micrograph of the as-received Ti-10V-1Fe$-3 \mathrm{Al}$ alloy, (b) SEM micrograph of the as-received Ti-10V$-2 \mathrm{Cr}-3 \mathrm{Al}$ alloy, and (c) XRD patterns of the as-received alloys.

lowing the standard metallographic preparation. Standard Kroll's reagent $\left(3 \mathrm{ml} \mathrm{HF}+6 \mathrm{ml} \mathrm{HNO}_{3}+100 \mathrm{ml}\right.$ $\mathrm{H}_{2} \mathrm{O}$ ) was used for revealing the microstructure. The microstructural evaluation was performed using a Leica LF7M38 optical microscope. Phase analysis was carried out using X-ray diffraction (XRD) with Co K $\alpha$ radiation. Room temperature compression tests were carried out on heat-treated specimens at a strain rate of $10^{-3} \mathrm{~s}^{-1}$ using Gleeble 1500 machine. Each compression test was repeated three times. The fracture surface was observed by a JEOL scanning electron microscopy (SEM). Microhardness measurements were carried out using a Vickers indenter at a load of $2 \mathrm{~N}$ and making 10 independent measurements.

\section{Results}

\subsection{Grain growth kinetics}

The typical optical images and phase analysis of Ti-10V-1Fe-3Al and Ti-10V-2Cr-3Al alloys (wt.\%) after the heat treatment are shown in Fig. 3. It can be seen that the microstructure of the alloys has changed a lot after solution annealing at $900^{\circ} \mathrm{C}$. The primary $\alpha$ phase fully disappeared, and large $\beta$ grains are formed. A large amount of quenched martensite is precipitated after quenching. With the increase of solution time, the amount of quenched martensite decreases. However, the specific reasons are not clear yet; further investigation is needed. Comparing these two alloys, it was found that after solution treated at $900^{\circ} \mathrm{C}$ for 2 min, the amount of martensite in Ti-10V-1Fe-3Al alloy is relatively higher than that in Ti-10V-2Cr-3Al alloy, which is due to the different stability of the high-temperature $\beta$-phase evaluated by $M o$ equivalence $\left(M o_{\mathrm{eq}}\right)$ according to the equation in the form [11]:

$$
\begin{gathered}
M o_{\mathrm{eq}}=1.00 \mathrm{Mo}(\text { wt. } \%)+0.28 \mathrm{Nb}(\text { wt. } \%)+ \\
0.22 \mathrm{Ta}(\text { wt. } \%)+0.67 \mathrm{~V}(\text { wt. } \%)+1.6 \mathrm{Cr}(\text { wt. } \%)+ \\
2.9 \mathrm{Fe}(\text { wt. } \%)-1.00 \mathrm{Al}(\text { wt. } \%)
\end{gathered}
$$

The calculated $M o_{\text {eq }}$ value is 6.5 and 7.6 for Ti$-10 \mathrm{~V}-1 \mathrm{Fe}-3 \mathrm{Al}$ and $\mathrm{Ti}-10 \mathrm{~V}-2 \mathrm{Cr}-3 \mathrm{Al}$ alloy, respectively. To qualitatively understand the influence of grain size on the properties of the alloys, the microhardness of two titanium alloys with different grain sizes was tested, as shown in Fig. 4. It can be seen that the microhardness of both alloys decreases with the increase of grain size, but at the same time, the size of grains is sufficiently large in the studied alloys to guarantee that each microindentation remains within the individual grain. In this paper, we thought that with the increase of solution time, the distribution of alloying elements in and between grains is more homogeneous, which reduces the strengthening effect of alloying elements, thus reducing the hardness value. On the other hand, with the increase of solution time, the amount of martensite decreases after quenching (although the specific reason is not clear), which may also be one of the reasons for the decrease of hardness. Also, there is a contradiction between the decrease of hardness 

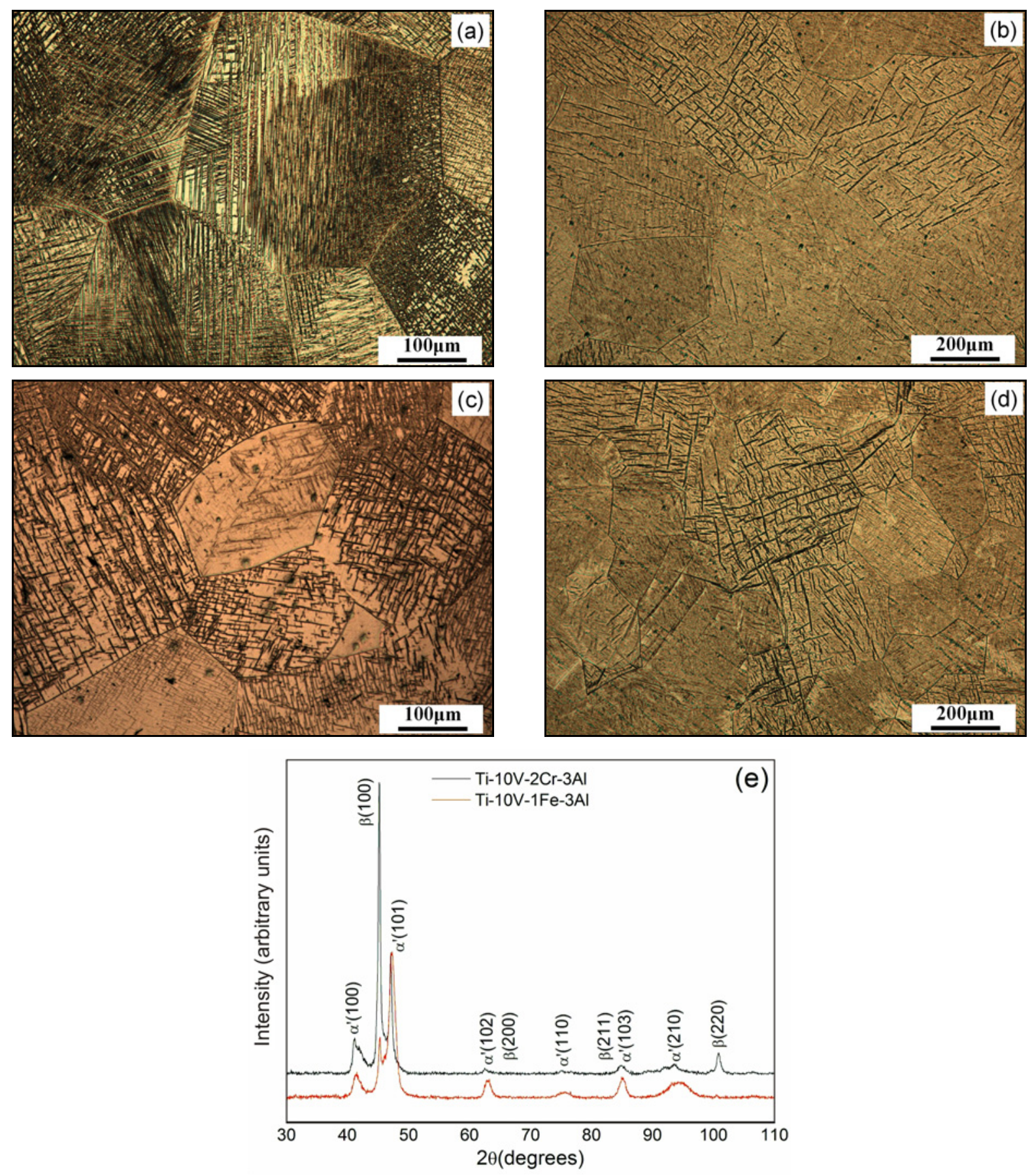

Fig. 3. (a) Optical images Ti-10V-1Fe-3Al alloy solution annealed at $900^{\circ} \mathrm{C} / 2 \mathrm{~min}$, (b) optical images Ti-10V-1Fe- $3 \mathrm{Al}$ alloy solution annealed at $900^{\circ} \mathrm{C} / 30 \mathrm{~min}$, (c) optical images Ti-10V-2Cr-3Al alloy solution annealed at $900^{\circ} \mathrm{C} / 2 \mathrm{~min}$, (d) optical images Ti-10V-2Cr-3Al alloy solution annealed at $900^{\circ} \mathrm{C} / 30 \mathrm{~min}$, and (e) XRD results of the solution annealed samples.

value and the slight increase of compressive strength on the stress-strain curve. We believe that this is due to the occurrence of stress-induced martensite transformation in the alloy and change of the original dislocation dominated work hardening mode, which makes the strength mechanism of the alloys more complex. More detailed quantitative research still needs to be carried out.
The grain size of two titanium alloys as a function of solution time is shown in Fig. 5. It can be seen from the curves that the grain size increases with the increase of solution time at $900^{\circ} \mathrm{C}$. The growth of $\beta$ grain is mainly composed of two processes: recrystallization nucleation and grain growth. In the stage of recrystallization nucleation, $\beta$ grains nucleate preferentially near the grain boundary, deformation band, inclusion, and remaining $\beta$-phase. After 


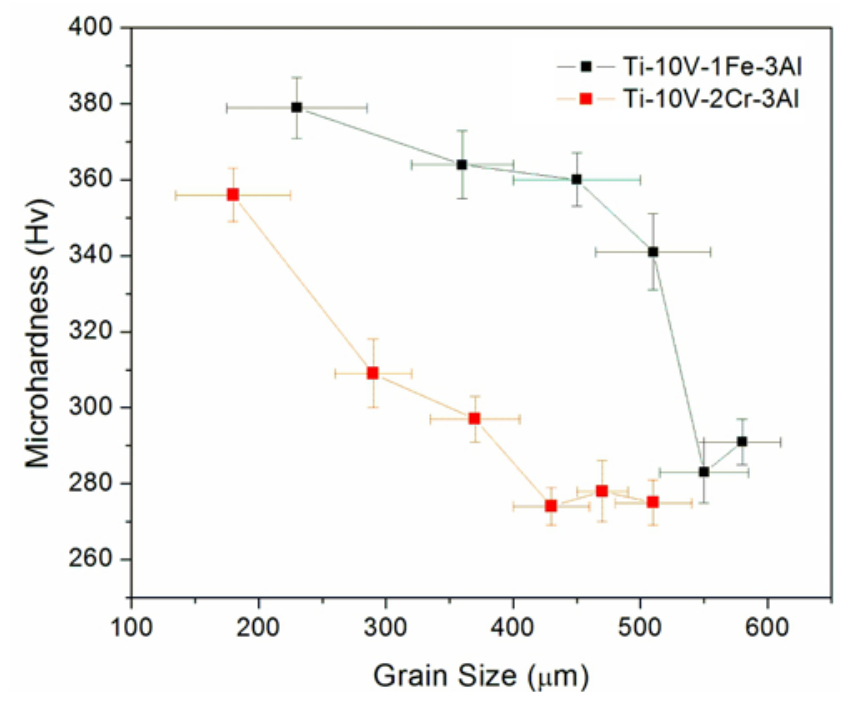

Fig. 4. Dependence of microhardness on grain size. The studied titanium alloys are shown in the figure.

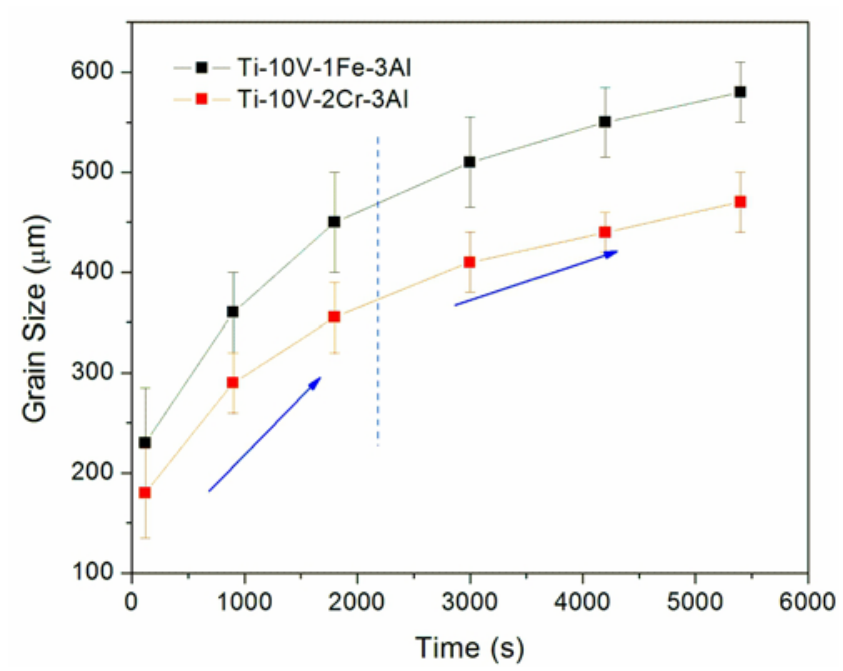

Fig. 5. Dependence of grain size on annealing time of the studied titanium alloys solution annealed at $900^{\circ} \mathrm{C}$.

the nucleation, the grains grow by gradually annexing the surrounding $\alpha$-phase. In this stage, the thermodynamic driving force of $\beta$ grain growth is the difference of free energy between $\alpha$ and $\beta$ until the $\alpha$-phase completely transforms into the $\beta$-phase. In the second stage, the driving force for $\beta$ grain growth is the deformation storage energy, and the grain growth is realized by the reduction of the total interface energy. The longer the solution time is, the more thoroughly the atoms diffusion and the larger the grain size is. According to the growth rate of different periods, the grain growth curve of the two alloys can be roughly divided into two stages, as shown in Fig. 5 . The growth rate at the solution annealing time shorter than $1800 \mathrm{~s}$
(30 min) is higher than that after $1800 \mathrm{~s}$. Generally speaking, with the extension of holding time at the solution temperature, the grain growth of titanium alloy conforms to the combined-power function model $(n<1)$, and its growth rate is relatively higher at the initial stage. With the increase of solution annealing time, the grain growth of the alloy is sufficient, which makes the total interface energy of the alloy decrease; the driving force of grain growth decreases, thus the growth rate decreases. Also, by comparing these two alloys, we can find that the grain growth rate of $\mathrm{Ti}-10 \mathrm{~V}-1 \mathrm{Fe}-3 \mathrm{Al}$ alloy is higher than that of Ti-10V-2Cr-3Al alloy under the same solid solution annealing conditions. The essence of grain growth is grain boundary migration, but the type and quantity of solute atoms have an important influence on it. The diffusion rate of $\mathrm{Cr}$ in $\mathrm{Ti}$ crystal is much slower than that of $\mathrm{Fe}$, so the drag effect of $\mathrm{Cr}$ on grain boundary is higher than that of Fe, which affects the grain growth rate of $\mathrm{Ti}-10 \mathrm{~V}-2 \mathrm{Cr}-3 \mathrm{Al}$ alloy $[17]$.

\subsection{Effect of grain size on the mechanical properties}

Figure 6 shows the typical true stress-strain curves of the studied alloys after solution annealing. It can be seen that the stress-induced martensitic transformation occurs in all specimens (double yield point on the stress-strain curve), as seen in Figs. 6a,b. The compressive deformation curves indicate that the high-temperature $\beta$-phase of the two alloys is unstable at room temperature, and the transformation can occur by applying external load (driving force), which is similar to some of our previous research results [2]. The deformed microstructure of the compression specimens clearly shows the formation of stress-induced transformations and confirms the observed differences in the compressive deformation curves, as seen in Fig. 6c. The stress-strain curves change with the increase of grain size, which indicates that the grain size has a great influence on the mechanical properties of the studied titanium alloys due to the stress-induced martensitic transformation.

Figure 7 shows the influence of grain size on the mechanical properties of the alloys. Figure 7 a shows the effect of grain size on the triggering stress in the studied titanium alloys. It can be seen from the figure that the triggering stress increases with the increase of the grain size. When the grain size is less than $400 \mu \mathrm{m}$, the increment of the triggering stress is small. When the grain size is greater than $400 \mu \mathrm{m}$, the increment of the triggering stress is more obvious. To clarify the effect of grain size on martensitic transformations, the following expression for the free energy change during the transformation from the metastable $\beta$ to the martensite proposed by Liu and Yang [18] and Bhat- 

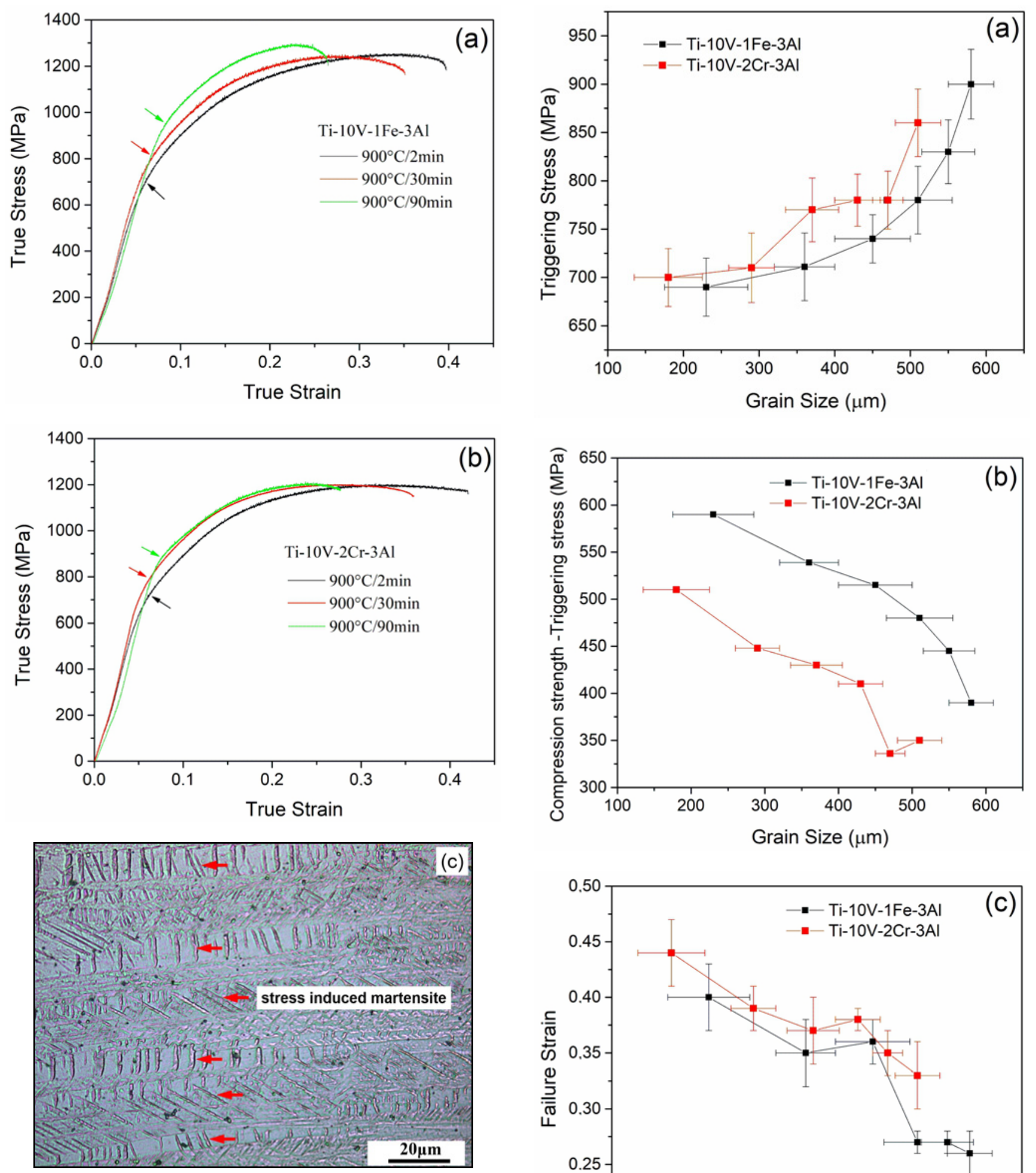

Fig. 6. (a) True stress-strain curves of different solution annealed Ti-10V-1Fe-3Al, (b) true stress-strain curves of different solution annealed Ti-10V-2Cr-3Al, and (c) typical microstructure of specimen showing stress induced martensitic transformation (Ti-10V-1Fe-3Al alloy with $900^{\circ} \mathrm{C} / 2$ min treatment).
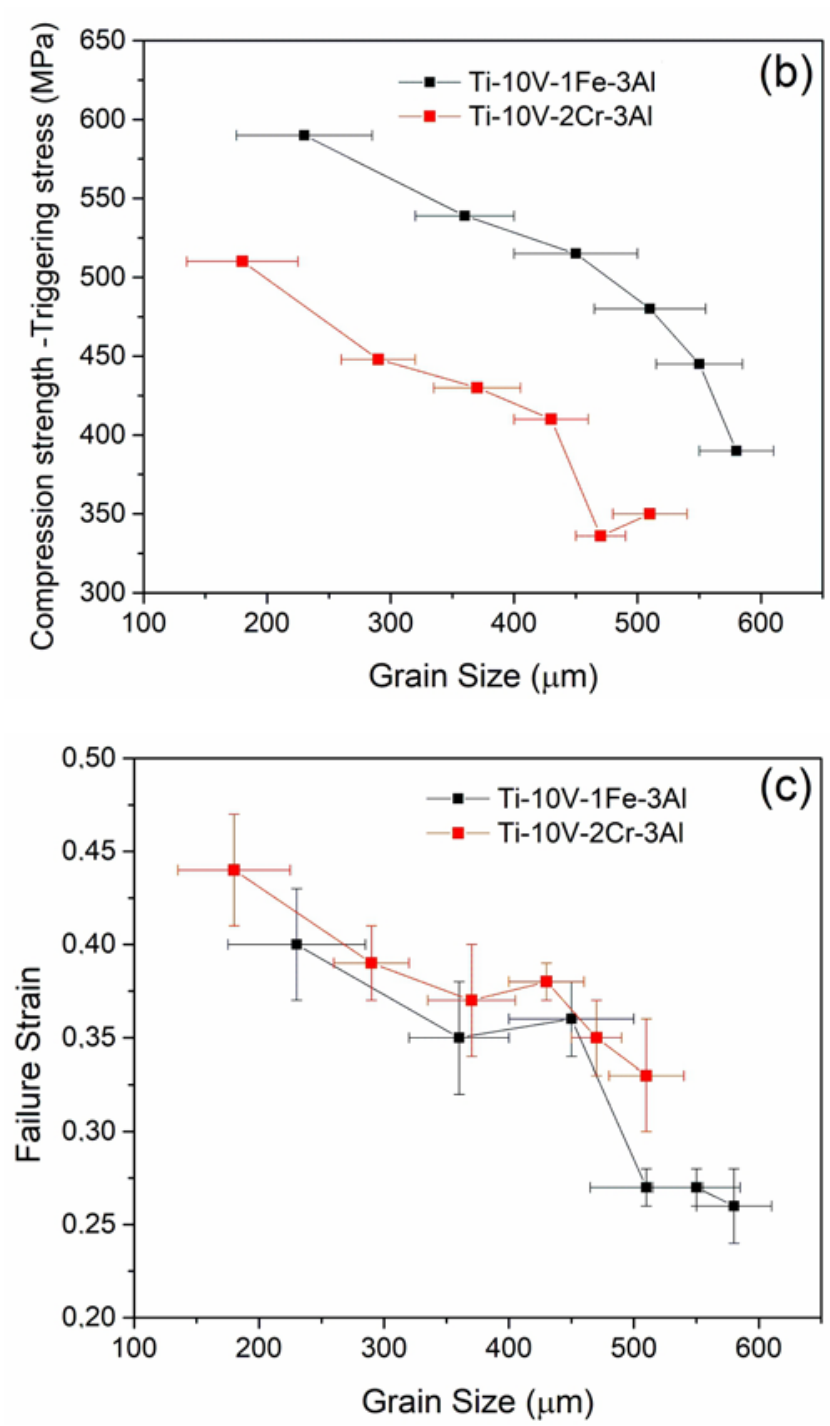

Fig. 7. The effect of grain size on room temperature compressive properties of the studied titanium alloys: (a) variation of triggering stress with grain size, (b) variation of work hardening ability with grain size, and (c) variation of failure compressive strain with grain size. 
tacharjee [19] can be applied:

$$
\begin{aligned}
\Delta G= & \Delta H-T \Delta S+\Delta E_{\mathrm{el}}+\delta E_{\mathrm{irr}}-\varepsilon_{\mathrm{tr}}- \\
& -\frac{1}{2}\left[f \frac{\sigma^{2}}{E_{\mathrm{M}}}-(1-f) \frac{\sigma^{2}}{E_{\beta}}\right]
\end{aligned}
$$

where $\Delta H$ is the enthalpy, $T$ is the test temperature, and $\Delta S$ is the entropy. The enthalpy $\Delta H$ and entropy $\Delta S$ of the system are independent of grain size $[20]$, so the term $(\Delta H-T \Delta S)$ should be independent of grain size. The term $\varepsilon_{\mathrm{tr}}$ is the force-displacement work associated due to lattice distortion of martensite, it is related to the material texture, and the term $\frac{1}{2}\left[f \frac{\sigma^{2}}{E_{\mathrm{M}}}-(1-f) \frac{\sigma^{2}}{E_{\beta}}\right]$ is the elastic energy created due to external stress because of the elastic elongation owing to the difference in elastic modulus of $\beta$ and $\alpha^{\prime \prime}[19]$. Both terms do not vary with grain size either. However, the stored internal elastic energy $\left(\Delta E_{\mathrm{el}}\right)$ and irreversible energy for work done in overcoming internal friction $\left(\delta E_{\text {irr }}\right)$ are parameters that vary with $\beta$ grain size dependence.

According to Sakamoto [21], the martensite plate length plays an important role in defining the magnitude of the internal stress field generated in the matrix. For a given volume of martensite, decreasing the plate size decreases the $\Delta E_{\mathrm{el}}$. Since the mean length and width of martensitic plates are governed by the grain size, the specimens containing smaller grains have a lower $\Delta E_{\text {el }}$ value. Olson et al. [22] and Bhattacharjee et al. [19] suggested that the frictional resistance is proportional to the volume swept by the interface which also depends on the grain size. For a given volume fraction of martensite, decreasing the plate size increases the $\delta E_{\text {irr }}$, meaning during the stress-induced transformation, samples containing smaller grains have a higher $\delta E_{\text {irr }}$ value. The relationship between $\beta$-grain size and the triggering stress deduced in this research shows a positive trend, which means that for the grain sizes studied in the present work, the overall contribution of $\Delta E_{\mathrm{el}}$ and $\delta E_{\mathrm{irr}}$ terms to the SIM triggering stress is positive. It is worth noting that the increase in triggering stress with grain size is in good agreement with prior work [19, 23].

To clarify the effect of stress-induced martensitic transformation on the mechanical properties more clearly, the difference between the compressive strength and triggering stress is used as a parameter to characterize the work hardening ability of the alloys. The results are shown in Fig. 7b. It can be seen that with the increase of grain size, the work hardening ability of the two alloys decreases rapidly. Li et al. [17] have shown that the metastable $\beta$-phase with nominal $M o_{\text {eq }}$ value between 6 and 15 can produce stress-induced martensitic transformation under relatively low external loading. This transformation can improve the work hardening ability of the alloy, which is regarded as a potential strengthening mechanism for titanium alloys. In the present study, the increase of grain size leads to the gradual increase of the triggering stress, which indicates that the difficulty of SIM increases and subsequently, the corresponding strengthening effect decreases. The stress-strain curve showed a decline in work hardening ability.

The effect of grain size on the failure strain of the two alloys is shown in Fig. 7c. It can be seen that with the increase of grain size, the failure strain values also show downward trends. On the one hand, the deformation can be dispersed in finer grains under the same deformation condition, which makes the deformation of each grain more uniform. The fine structure grain contains more grain boundaries, which prevent the propagation of cracks, and the alloy shows good plasticity before fracture. On the other hand, the deformation is easy to occur only in a few coarse grains, which causes serious deformation concentration and low plasticity of coarse-grained alloy before fracture. In summary, the grain size of the alloy is one of the main factors affecting the mechanical properties and it should be reasonably controlled according to the actual needs to achieve a good match of the mechanical properties.

\subsection{Fracture surface observation}

The typical fracture morphology is shown in Fig. 8. It can be seen that with the increase of grain size, the fracture surface of the alloy changes slightly. Figure $8 \mathrm{a}$ shows a relatively flat surface of Ti-10V-1Fe-3Al alloy with a grain size of $\sim 230 \mu \mathrm{m}$. There are two different featured areas. One is the tiny dimple area, as shown in Fig. 8b. Some of these dimples are small in size, and the other ones are seriously elongated along the direction of fracture due to the external stress. Other regions are featureless smooth regions, which are distributed between dimple areas, as shown in Fig. 8c. Most of the materials can show good plasticity in compression. Under large compressive deformation, some fracture areas can be severely scratched and some original fracture areas can be easily damaged, which results in such smooth regions as shown in Figs. 8d-f.

\section{Conclusions}

The effect of $\beta$ grain size on the mechanical response of $\mathrm{Ti}-10 \mathrm{~V}-1 \mathrm{Fe}-3 \mathrm{Al}$ and $\mathrm{Ti}-10 \mathrm{~V}-2 \mathrm{Cr}-3 \mathrm{Al}$ alloys was studied. The main conclusions can be summarized as follows:

1. The grain size increases with the increase of solution annealing time. The grain growth curve of both alloys can be roughly divided into two stages. The grain growth rate of $\mathrm{Ti}-10 \mathrm{~V}-1 \mathrm{Fe}-3 \mathrm{Al}$ alloy is higher than that of $\mathrm{Ti}-10 \mathrm{~V}-2 \mathrm{Cr}-3 \mathrm{Al}$ alloy under the same 

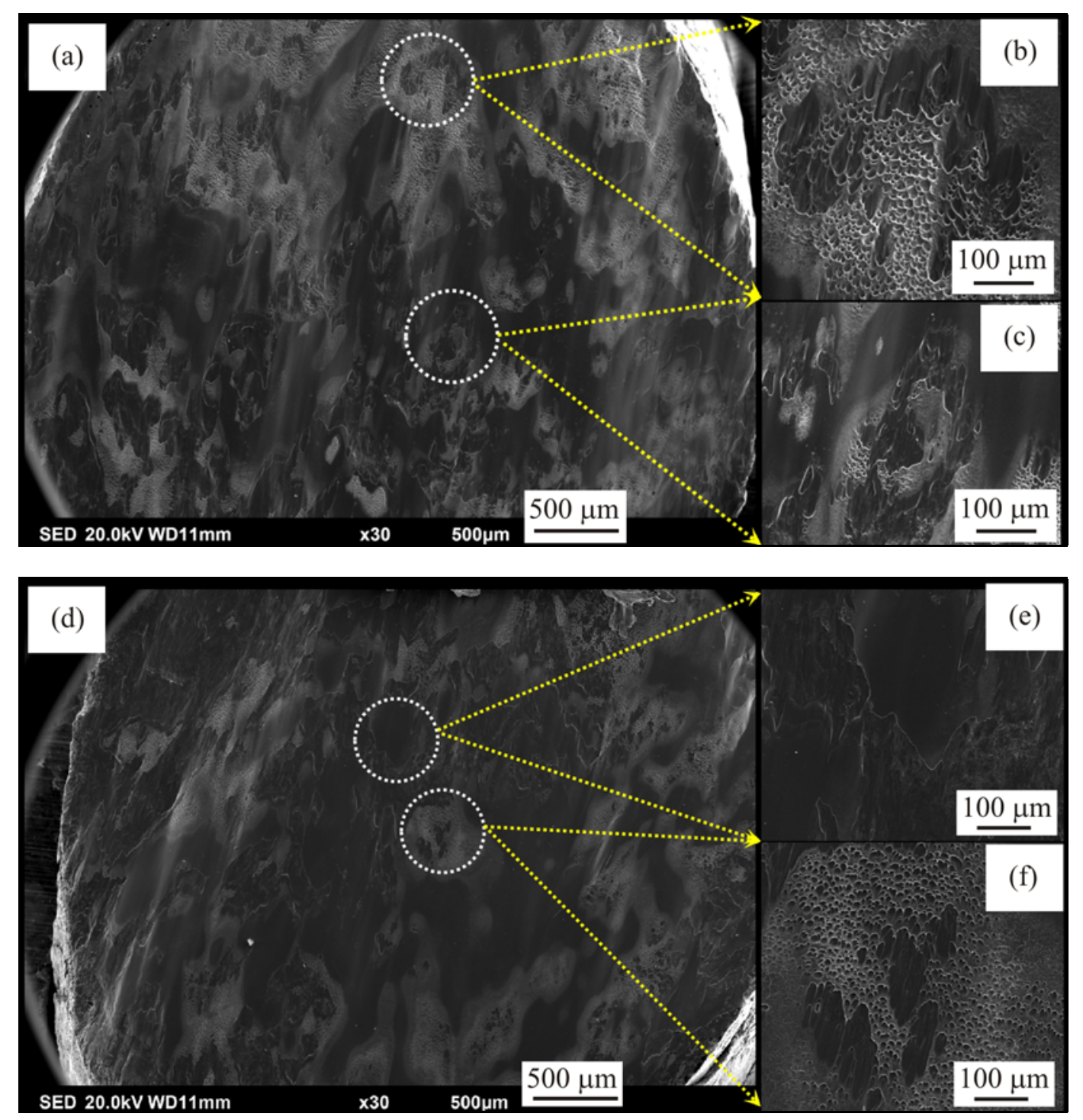

Fig. 8. Fracture surface of compression specimens with different grain size: (a) Ti-10V-1Fe-3Al alloy with average grain size of $\sim 230 \mu \mathrm{m}$; (b) and (c) enlarged details of fracture surface of Ti-10V-1Fe-3Al alloy with average grain size of $\sim 230 \mu \mathrm{m}$; (d) Ti-10V-1Fe-3Al alloy with average grain size of $\sim 500 \mu \mathrm{m}$; (e) and (f) enlarged details of fracture surface of Ti-10V-1Fe-3Al alloy with average grain size of $\sim 500 \mu \mathrm{m}$.

solid solution annealing conditions.

2. Stress-induced martensitic transformation occurs in specimens with fully $\beta$-phase under compression. The triggering stress increases with the increase of grain size, which means that the effect of the martensitic phase transformation is restrained gradually with increasing grain size.

3. The work hardening ability and failure strain of the studied alloys decrease with the increase of grain size. Fracture surface observations show a good agreement with the evolution of compressive properties with the grain size.

\section{Acknowledgements}

The authors gratefully acknowledge the financial sup- port provided by the National Natural Science Foundation of China (Grant No. 51775055, 51975061), Natural Science Foundation of Hunan Province (2018JJ3539, 2019JJ40300), Research Foundation of Education Bureau of Hunan Province (Grant No. 19B033), China Postdoctoral Science Foundation (No. 2018M642973), and State Key Laboratory of Advanced Design and Manufacturing for Vehicle Body at Hunan University (No. 31875004).

\section{References}

[1] C. Leyens, M. Peters, Titanium and Titanium alloys, Wiley-CVH Verlag GmbH\&Co. KGaA, Weinheim, Germany, 2003.

[2] C. Li, L. Qin, M. Li, H. Xiao, Q. Wang, J. Chen, Influence of deformation strain rate on the mechanical 
response in a metastable $\beta$ titanium alloy with various microstructures, J. Alloy Compd. 815 (2020) 152426. doi:10.1016/j.jallcom.2019.152426

[3] C. Li, H. Li, S. van der Zwaag, Unravelling the abrasion resistance of two novel meta-stable titanium alloys on the basis of multi-pass-dual-indenter test, Wear 400-441(2019) 203094. doi:10.1016/j.wear.2019.203094

[4] F. J. Gil, J. A. Planell, A. Padrós, C. Aparicio, The effect of shot blasting and heat treatment on the fatigue behaviour of titanium for dental implant applications, Dental Mater. 23 (2007) 486-491. doi:10.1016/j.dental.2006.03.003

[5] C. Li, M. Li, H. Li, J. Chen, H. Xiao, Influence of solution treatment on microstructural evolution and mechanical properties of a new titanium alloy, Kovove Mater. 58 (2020) 41-48. doi:10.4149/km_2020_1_41

[6] S. Neelakantan, D. S. Martin, P. E. J. Rivera-Diaz-delCastillo, S. van der Zwaag, Prediction of the martensite start temperature for $\beta$ titanium alloys as a function of composition, Scripta Mater. 60 (2009) 611-614. doi:10.1016/i.scriptamat.2008.12.034

[7] J. D. Cotton, J. F. Bingert, P. S. Dunn, Microstructure and mechanical properties of Ti-40Wt Pct Ta (Ti-15 At. Pct Ta), Metall. Mater. Trans. 25 (1994) 461-472. doi:10.1007/BF02651588

[8] H. Ohyama, T. Nishmura, Effects of alloying elements on deformation mode in Ti-V based alloy system, Iron and Steel Institute of Japan 35 (1995) 927-936. doi:10.2355/isijinternational.35.927

[9] L. C. Zhang, T. Zhou, M. Mindow, Nucleation of stress-induced martensite in a Ti/Mo-based alloy, J. Mater. Sci. 40 (2005) 2833-2836. doi:10.1007/s10853-005-2426-5

[10] S. Sembosh, T. Shirai, T. Konno, In-suit transmission electron microscopy observation on the phase transformation of Ti-Nb-Sn shape memory alloys, Metall. Mater. Trans. A 39 (2008) 2820-2829. doi:10.1007/s11661-008-9674-3

[11] C. Li, X. Wu, J. Chen, S. van der Zwaag, Influence of $\alpha$ morphology and volume fraction on the stress-induced martensitic transformation in Ti-10V-2Fe-3Al, Mater. Sci. Eng. A 528 (2011) 5854-5860. doi:10.1016/j.msea.2011.03.107

[12] C. Li, J. Chen, W. Li, J. J. He, W. Qiu, Y. J. Ren, J. L. Chen, J. H. Chen, Study on the relationship between microstructure and mechanical property in a metastable $\beta$ titanium alloy, J. Alloy Compd. 627 (2015) 222-230. doi:10.1016/i.jallcom.2014.12.100
[13] C. Li, J. Chen, W. Li, Y. Ren, J. He, Z. Song, Effect of heat treatment variations on the microstructure evolution and mechanical properties in a $\beta$ metastable Ti alloy, J Alloy Compd. 684 (2016) 466473. doi:10.1016/j.jallcom.2016.05.225

[14] T. Grosdidier, Y. Combres, E. Gautier, Effect of microstructure variations on the formation of deformation induced martensite and associated tensile properties in a $\beta$ metastable Ti alloy, Metall. Mater. Trans. A 31 (2000) 1095-1106. doi:10.1007/s11661-000-0105-3

[15] A. Bhattacharjee, S. Bhargava, V. K. Varma, Effect of $\beta$ grain size on stress induced martensitic transformation in $\beta$ solution treated Ti-10V-2Fe-3Al alloy, Scripta Materialia 53 (2005) 195-200. doi:10.1016/j.scriptamat.2005.03.039

[16] A. Paradkar, S. V. Kamat, A. K. Gogia, Trigger stress for stress induced martensitic transformation during tensile deformation in Ti-Al-Nb alloys: effect of grain size, Metall. Mater. Trans. A 39 (2008) 551558. doi:10.1007/s11661-007-9432-y

[17] C. Li, J. Chen, X. Wu, W. Wang, S. van der Zwaag, Tuning the stress induced martensitic formation in titanium alloys by alloy design, J. Mater. Sci. 47 (2012) 4093-4100. doi:10.1007/s10853-012-6263-z

[18] Y. Liu, H. Yang, The concern of elasticity in stress-induced martensitic transformation in NiTi, Mater. Sci. Eng. A 260 (1999) 240-245. doi:10.1016/S0921-5093(98)00959-9

[19] A. Bhattacharjee, S. Bhargava, V. K. Varma, S. V. Kamat, A. K. Gogia, Effect of $\beta$ grain size on stress induced martensitic transformation in $\beta$ solution treated Ti-10V-2Fe-3Al alloy, Scripta Mater. 53 (2005) 195200. doi:10.1016/j.scriptamat.2005.03.039

[20] B. Appolaire, L. Héricher, E. Gautier, Modelling of phase transformation kinetics in Ti alloys - Isothermal treatments, Acta Mater. 53 (2005) 3001-3011. doi:10.1016/j.actamat. 2005.03.014

[21] H. Sakamoto, Distinction between thermal and stressinduced martensitic transformations and inhomogeneity in internal stress, Mater. Trans. JIM 43 (2002) 2249-2255. doi:10.2320/matertrans.43.2249

[22] G. B. Olson, M. Cohen, Thermoelastic behavior in martensitic transformations, Scripta Metall. 9 (1975) 1247-1254. https://doi:10.1016/0036-9748(75)90418-4

[23] A. Bhattacharjee, V. K. Varma, S. V. Kamat, A. K. Gogia, S. Bhargava, Influence of $\beta$ grain size on tensile behavior and ductile fracture toughness of titanium alloy Ti-10V-2Fe-3Al, Metall. Mater. Trans. A 37 (2006) 1423-1433. doi:10.1007/s11661-006-0087-x 